\title{
Micromechanics-Based Prediction Models and Experimental Validation on Elastic Modulus of Recycled Aggregate Concrete
}

\author{
Shirong Yan ${ }^{1}$, Binglei Wang ${ }^{1,2, *(\mathbb{D})}$, Yu Sun ${ }^{1}$ and Boning Lyu ${ }^{1}$ \\ 1 School of Civil Engineering, Shandong University, Jinan 250061, China; yanshirong0516@163.com (S.Y.); \\ 202035040@mail.sdu.edu.cn (Y.S.); 202035031@mail.sdu.edu.cn (B.L.) \\ 2 Urban and Rural Solid Waste Comprehensive Utilization Research Institute, Shandong University, \\ Tai'an 271000, China \\ * Correspondence: bwang@sdu.edu.cn
}

check for updates

Citation: Yan, S.; Wang, B.; Sun, Y.; Lyu, B. Micromechanics-Based Prediction Models and Experimental Validation on Elastic Modulus of Recycled Aggregate Concrete. Sustainability 2021, 13, 11172. https:/ / doi.org/10.3390/su132011172

Academic Editor: Jorge de Brito

Received: 22 September 2021

Accepted: 8 October 2021

Published: 10 October 2021

Publisher's Note: MDPI stays neutral with regard to jurisdictional claims in published maps and institutional affiliations.

Copyright: (c) 2021 by the authors. Licensee MDPI, Basel, Switzerland. This article is an open access article distributed under the terms and conditions of the Creative Commons Attribution (CC BY) license (https:/ / creativecommons.org/licenses/by/ $4.0 /)$.

\begin{abstract}
Elastic modulus is one of the most important mechanical properties of concrete (including recycled aggregate concrete), and it has a notable guiding significance for engineering. There is a lack of micromechanical research on the elastic modulus of recycled aggregate concrete. This paper adopts four models based on micromechanics, including the Voigt model, Reuss model, Eshelby method, and Mori-Tanaka method, to predict the elastic modulus of recycled aggregate concrete. The optimal model is determined by comparing the results of the four models with the experimental data. On this basis, some previous prediction methods for the elastic modulus of concrete are employed to be compared with the most satisfactory models in this paper. Several experimental data from the open literature are also utilized to better illustrate the reliability of the prediction models. It is concluded that the Mori-Tanaka method unfailingly produces more accurate predictions compared to other models. It gives the best overall approximation for various data and has extensive effects in predicting the elastic modulus of RAC. This work may be helpful in promoting the development of micromechanics research in recycled aggregate concrete.
\end{abstract}

Keywords: recycled aggregate concrete (RAC); elastic modulus; recycled coarse aggregate (RCA); micromechanics

\section{Introduction}

With the large-scale reconstruction of old villages and infrastructure construction, a large amount of construction waste has been generated along with various construction activities. For instance, according to the "Annual Report on China's Comprehensive Utilization of Resource (2014)", 500 million tons of construction waste was produced in 2009, which has significantly doubled in 2013. According to construction waste yield estimates, in 2018, the annual yield of construction waste reached approximately 1875.79 million tons [1]. If construction waste reduction management and resource utilization cannot be implemented in time, the output of construction waste will continue to rise in the future. In addition, China's large-scale construction activities have brought about the shortage of sand and gravel resources as raw materials for construction materials and the problem of skyrocketing prices. Therefore, the resource utilization of construction waste is an imperative and general trend.

Using waste concrete in construction waste as raw materials to make recycled aggregates and reapplying them in construction activities are some of the most important measures for the resource utilization of construction waste. Recycled coarse aggregate (RCA) for concrete refers to particles with a particle size greater than $4.75 \mathrm{~mm}$ that are processed from construction waste or concrete, mortar, stones, bricks, etc., used in the preparation of concrete [2]. Compared with natural coarse aggregate (NCA), RCA has the disadvantages of low density, high water absorption, high crushing value, and worse durability [3-5]. The quality of coarse aggregates has an evident impact on the performance 
of finished concrete. Therefore, many scholars have conducted a large number of studies to improve the properties of RCA, such as the removal of attached mortar, carbonization reinforcement (C-RAC), lime carbonation reinforcement (LC-RAC), and biomineralization reinforcement, etc. [6-9]. In addition, the research on recycled aggregate concrete (RAC) made of RCA mainly focuses on its mechanical properties, deformation properties, pore structure characteristic, and durability [10-15]. Kazmi et al. [16] propose an innovative concrete casting approach to achieve the strength of RAC including RCA and chipped rubber (CR) similar to NAC. Results show that the compressive strength and elastic modulus of compressed RAC and treated RAC incorporating 10-20\% of CR in replacement of coarse aggregates are quite close to NAC without CR. Moreover, the cost comparison and cement strength contribution index calculated also show the industrial application potential of the new casting approach. Moreover, research has been carried out on structural components such as RAC beams and columns [17-20]. However, the above researches are mainly based on experimental research and numerical simulation, and the theoretical research on the mechanical properties of RAC is rare.

Elastic modulus is a dominant mechanical parameter of concrete (included RAC). From a macroscopic point of view, the elastic modulus is a measure of the ability of an object to resist elastic deformation. From a microscopic point of view, it is a reflection of the bonding strength between atoms, ions, or molecules. The research on the elastic modulus of RAC is mainly based on experimental measurement [21-23], besides some studies using computer methods to predict elastic modulus. Golafshani et al. [24] utilized four types of soft computing methods, namely, artificial neural network (ANN), fuzzy TSK, support vector regression (SVR), and radial basis function neural network (RBFNN) to predict the 28 day elastic modulus of RAC (ERAC). The results showed that the proposed models based on the SVR and ANN techniques were more precise. Han et al. [25] presented an ensemble machine learning (ML) model for the prediction of elastic modulus of RAC, and the prediction performance of the ensemble ML model was compared with five commonly used ML models. The result showed the ensemble ML model produced more accurate predictions compared to standalone models.

Whether it is natural aggregate concrete (NAC) or RAC, they can all be regarded as composite materials. The composite material itself has strong structural characteristics. It is a multibody (matrix, reinforced or toughened phase, equal interface) material. Therefore, its performance and damage rule not only depend on the properties of its component materials but also its microstructure characteristics. To reveal the influence of the microscopic characteristics and component materials of RAC on their elastic modulus, micromechanics is very useful. The elastic modulus of concrete is known to be a function of the elastic modulus of the components. At present, some scholars use micromechanics models to predict the elastic modulus of NAC. Counto [26] proposed a new model by discussing some micromechanics models currently available for the prediction of elastic modulus of concrete. This new model gave a satisfactory elastic modulus prediction for a wide variety of aggregates and concrete mixes. The same model can explain the isolated effect of the elastic modulus of the aggregate on both the creep and creep recovery of concrete. Chang et al. [27] divided carbonated concrete into three zones, including the full carbonation zone, partial carbonation zone, and noncarbonation zone. A three-layer inclusion model of composite materials was adopted to calculate the effective elastic modulus. The results of the compressive strength and elastic modulus increased with an increase in the degree of carbonation but conversely for ductility. It also proved using the three-layer inclusion model of composite materials theory could accurately predict the elastic modulus of carbonated concrete specimens. Few studies use micromechanical models to predict the elastic modulus of RAC aside from these studies.

This paper adopts four models in micromechanics, including the Voigt model, Reuss model, Eshelby method, and Mori-Tanaka method. In addition, they are employed to obtain four prediction models of the elastic modulus of RAC. The compressive strength and elastic modulus experiments of RAC are conducted to verify the accuracy and robustness 
of the micromechanics-based prediction models. On this basis, some prediction methods for the elastic modulus of concrete proposed in the previous literature are employed to be compared with the most satisfactory models in this paper. Several experimental data from the open literature are also utilized with the experiment data of this paper to better illustrate the reliability of the prediction models. This work may provide a certain theoretical basis for predicting the elastic modulus of RAC and may promote the development of micromechanics in RAC research.

\section{Theoretical Models}

Four models in micromechanics, including the Voigt model, Reuss model, Eshelby method, and Mori-Tanaka method, are employed in this paper. Figure 1 shows the schematic of the prediction models for the elastic modulus of the RAC.

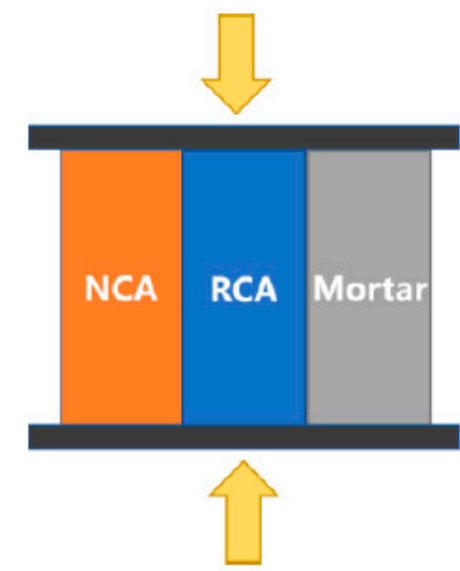

(a)

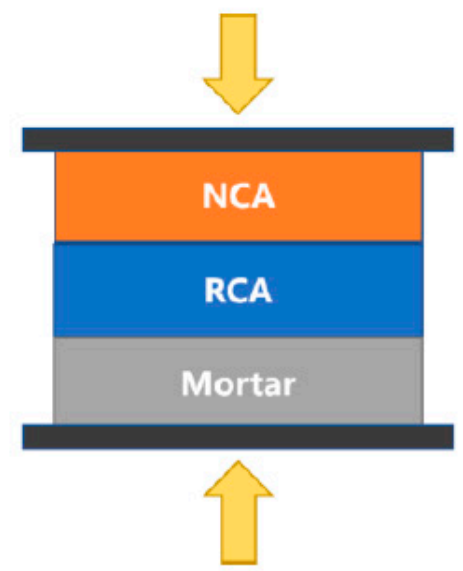

(b)

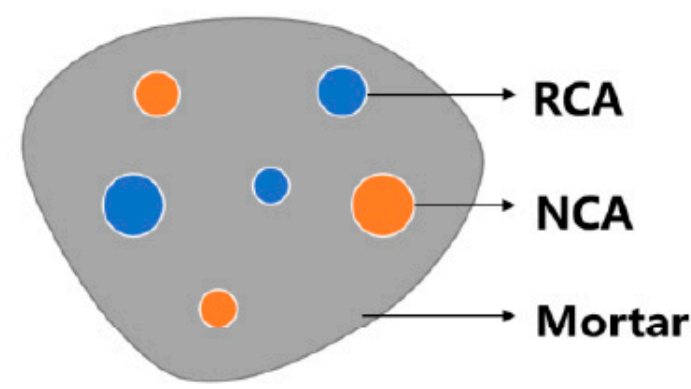

(c)

Figure 1. Different distribution schematic of recycled aggregate concrete (RAC). (a) Voigt model; (b) Reuss model; and (c) inclusion in the matrix. Note: RCA and NCA are the abbreviations for recycled coarse aggregate and natural coarse aggregate, respectively.

\subsection{Voigt Model and Reuss Model}

The Voigt model and Reuss model are the two simplest and classic models for estimating the elastic modulus of composite materials $[28,29]$. When the composite material is composed of two matrix materials, similar to the series and parallel in the circuit, the two matrix materials in the Voigt model are parallel structures that are based on the equal strain assumption. While in the Reuss model, the two matrix materials are the tandem structures that are in the view of the equal stress assumption. Both models ignore the lateral deformation. As shown in Figure 1a,b, the following section considers the situation where RAC is in uniaxial compression.

For the Voigt model, the elastic modulus of RAC $\left(E_{R A C}\right)$ is given by

$$
\mathrm{E}_{\mathrm{RAC}}=\sum_{\mathrm{r}=0}^{2} \mathrm{C}_{\mathrm{r}} \mathrm{E}_{\mathrm{r}}
$$

where the subscript $r$ represents mortar, NCA, and RCA. $C_{r}$ is the volume fraction of the material, and $\mathrm{E}_{\mathrm{r}}$ is the elastic modulus of the material.

For the Reuss model, the elastic modulus is given by

$$
\mathrm{E}_{\mathrm{RAC}}=\left(\sum_{\mathrm{r}=0}^{2} \mathrm{C}_{\mathrm{r}} \frac{1}{\mathrm{E}_{\mathrm{r}}}\right)^{-1}
$$


It is worth mentioning that the stiffness of a material is usually measured by the elastic modulus E. In the macroscopic elastic range, the stiffness is the force required to cause a unit displacement. Its reciprocal $1 / \mathrm{E}$ is called compliance, which is the displacement caused by unit force.

According to the previous works, it can be seen that the results of the Voigt model and Reuss model correspond to the upper and lower bound of the true elastic modulus, respectively $[28,29]$.

\subsection{Eshelby Method}

In 1957, Eshelby $[30,31]$ published an article on the issue of elastic fields containing ellipsoidal inclusions in infinite bodies. The author gives a general solution of the elastic field inside and outside the ellipsoid for ellipsoid particles with intrinsic strain.

As shown in Figure 1c, this paper only considers spherical inclusions to calculate its elastic modulus for composite materials such as RAC. Therefore, it assumes that all particles are spherical and randomly dispersed throughout the matrix. Further, it assumes that both the particle and the matrix are made of isotropic elastic materials. For RCA, the matrix is mortar, and the spherical particles are contained in the matrix including NCA and RCA.

The bulk modulus $\mathrm{K}_{\mathrm{RAC}}$ and shear modulus $\mathrm{G}_{\mathrm{RAC}}$ of RAC can be expressed as [28].

$$
\begin{gathered}
\mathrm{K}_{\mathrm{RAC}}=\mathrm{K}_{0}+\sum_{\mathrm{r}=1}^{2} \frac{\mathrm{C}_{\mathrm{r}}\left(\mathrm{K}_{\mathrm{r}}-\mathrm{K}_{0}\right)\left(3 \mathrm{~K}_{0}+4 \mathrm{G}_{0}\right)}{3 \mathrm{~K}_{\mathrm{r}}+4 \mathrm{G}_{0}} \\
\mathrm{G}_{\mathrm{RAC}}=\mathrm{G}_{0}+\sum_{\mathrm{r}=1}^{2} \frac{5 \mathrm{C}_{\mathrm{r}} \mathrm{G}_{0}\left(\mathrm{G}_{\mathrm{r}}-\mathrm{G}_{0}\right)\left(3 \mathrm{~K}_{0}+4 \mathrm{G}_{0}\right)}{3 \mathrm{~K}_{0}\left(3 \mathrm{G}_{0}+2 \mathrm{G}_{\mathrm{r}}\right)+4 \mathrm{G}_{0}\left(2 \mathrm{G}_{0}+3 \mathrm{G}_{\mathrm{r}}\right)}
\end{gathered}
$$

where $\mathrm{K}_{\mathrm{r}}$ and $\mathrm{G}_{\mathrm{r}}$ are, respectively, bulk modulus and shear modulus of the component material.

It is worth mentioning that this method is limited to low (dilute) concentrations of inhomogeneities because the distribution of the inhomogeneities is neglected. More importantly, the interaction between the inhomogeneities is not taken into consideration. That is why this method is also named the dilute concentration method [32].

\subsection{Mori-Tanaka Method}

In 1973, Mori and Tanaka [33] studied the work of the hardening of the dispersion hardening materials. At the time, the back stress method to solve the average stress inside the material was proposed, namely the Mori-Tanaka method. Because this method operates easily, it also takes into account the composite materials to a certain extent. The interaction between the inclusion phases has been widely used in recent years and has become one of the effective means to homogenize the properties of composite materials. Figure 1c is also the schematic diagram of its inclusion model. The bulk modulus $\mathrm{K}_{\mathrm{RAC}}$ and shear modulus $\mathrm{G}_{\mathrm{RAC}}$ of RAC can be expressed as

$$
\begin{gathered}
\mathrm{K}_{\mathrm{RAC}}=\mathrm{K}_{0}+\sum_{\mathrm{r}=1}^{2} \frac{\mathrm{C}_{\mathrm{r}}\left(\mathrm{K}_{\mathrm{r}}-\mathrm{K}_{0}\right)\left(3 \mathrm{~K}_{0}+4 \mathrm{G}_{0}\right)}{3 \mathrm{~K}_{\mathrm{r}}+4 \mathrm{G}_{0}+3\left(1-\mathrm{C}_{\mathrm{r}}\right)\left(\mathrm{K}_{\mathrm{r}}-\mathrm{K}_{0}\right)} \\
\mathrm{G}_{\mathrm{RAC}}=\mathrm{G}_{0}+\sum_{\mathrm{r}=1}^{2} \frac{5 \mathrm{C}_{\mathrm{r}} \mathrm{G}_{0}\left(\mathrm{G}_{\mathrm{r}}-\mathrm{G}_{0}\right)\left(3 \mathrm{~K}_{0}+4 \mathrm{G}_{0}\right)}{5 \mathrm{G}_{0}\left(3 \mathrm{~K}_{0}+4 \mathrm{G}_{0}\right)+6\left(1-\mathrm{C}_{\mathrm{r}}\right)\left(\mathrm{G}_{\mathrm{r}}-\mathrm{G}_{0}\right)\left(\mathrm{K}_{0}+2 \mathrm{G}_{0}\right)}
\end{gathered}
$$

Although the Mori-Tanaka method is also based on the assumption of spherical inclusions, the Mori-Tanaka method is suitable for composite materials with the inclusions of any volume fraction. In other words, it has a wider range of applications than the Eshelby method.

In addition, the use the relationship between elastic modulus, bulk modulus, and shear modulus

$$
E_{\text {RAC }}=\frac{9 K_{\text {RAC }} G_{\text {RAC }}}{G_{\text {RAC }}+3 K_{\text {RAC }}}
$$


to obtain the elastic modulus of RAC on different prediction methods, where $E_{R A C}$ is the elastic modulus of RAC, $K_{R A C}$ is bulk modulus, and $G_{R A C}$ is shear modulus, respectively.

\section{Experiments}

\subsection{Materials}

Experimental materials include the ordinary Portland cement (OPC, cement mark is 42.5R), natural river sand (medium sand in China National Standard GB/T 14684-2011 [34]), NCA whose diameters range from $5-20 \mathrm{~mm}$ with continuous grading, as well as RCA which is $5-20 \mathrm{~mm}$ continuous grading by crushing and processing waste concrete from the demolition of a building in Taian City, Shandong Province. Figure 2 presents the NCA and RCA, which are used in the experiment. Table 1 shows the main physical properties of NCA and RCA.

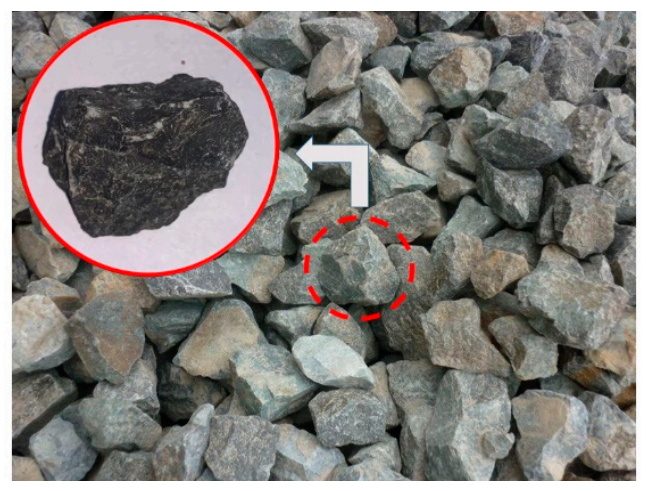

(a)

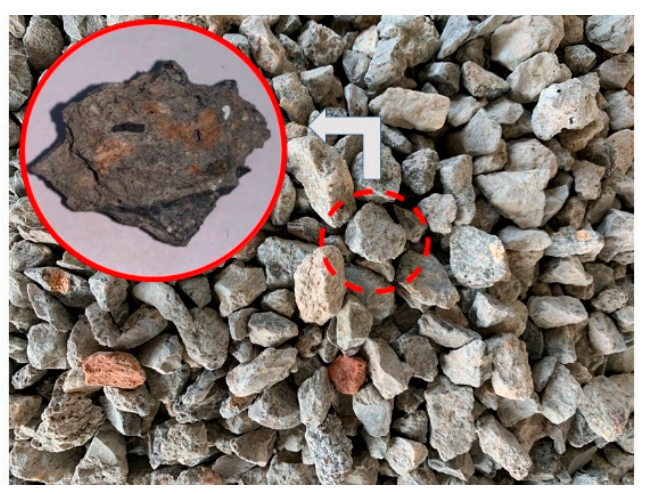

(b)

Figure 2. (a) Natural aggregate concrete (NCA) and (b) recycled coarse aggregate (RCA) were used in the experiment.

Table 1. Main physical properties of natural aggregate concrete (NCA) and recycled coarse aggregate (RCA).

\begin{tabular}{ccccc}
\hline \multirow{2}{*}{ Property } & \multirow{2}{*}{ NCA } & \multirow{2}{*}{ RCA } & \multicolumn{2}{c}{ Requirement/Category } \\
& & & GB/T 14685-2011 & GB/T 25177-2010 \\
\hline Apparent density $\left(\mathrm{kg} / \mathrm{m}^{3}\right)$ & 2660 & 2590 & $\geq 2600$ & Class I \\
Water absorption $(\%)$ & 0.7 & 4.8 & Class I & Class II \\
Crushing index $(\%)$ & 9.8 & 17.6 & Class I & Class II \\
Elongated or flat particle $(\%)$ & 5.0 & 9.0 & Class I & $<10$ \\
\hline
\end{tabular}

It can be seen that compared with NCA, the surface of RCA has attached mortar and contains some other ingredients, such as red bricks. The main properties were measured in accordance with China National Standard GB/T 14685-2011 [35] for NCA and GB/T 25177-2010 [2] for RCA. Considering the production process of RCA, excessive crushing may result in the development of microcracking and porosity within the attached mortar and deterioration of its physical properties. Thence, RCA tends to exhibit lower apparent density, higher water absorption, crushing index, and elongated or flat particle relative to those of NCA. Nevertheless, the physical properties of the NCA and RCA samples are all within the respective limits provided in GB/T 14685-2011 [34] and GB/T 25177-2010 [2].

\subsection{Concrete Mixture Proportions}

Zhang et al. [36] pointed out that additional water demand is required by the usual design due to the high water absorption of RCA and the water demand is calculated based on the 10 minutes water absorption of RCA also being added. This part of the water is called additional water. The specimens used in the experiment were designed according to $\mathrm{C} 30$ concrete. In this experiment, the water-cement ratio was 0.38 , and the sand ratio 
was 30\%. The recycled aggregate concrete (RAC) mixture proportions design is shown in Table 2. RAC is categorized into ten types according to their RCA replacement ratios, and the number in the name represents the value of the replacement ratio of RCA. No admixtures were added in this experiment by considering that concrete admixtures affect the strength of RAC and other indexes to a certain extent.

Table 2. Recycled aggregate concrete mixture proportions.

\begin{tabular}{ccccccc}
\hline Type & $\begin{array}{c}\text { Cement } \\
(\mathbf{k g})\end{array}$ & $\begin{array}{c}\text { Sand } \\
\mathbf{( k g )}\end{array}$ & $\begin{array}{c}\text { NCA } \\
\mathbf{( k g})\end{array}$ & $\begin{array}{c}\text { RCA } \\
\mathbf{( k g )}\end{array}$ & $\begin{array}{c}\text { Water } \\
\mathbf{( k g})\end{array}$ & $\begin{array}{c}\text { Additional } \\
\text { Water } \mathbf{( k g )}\end{array}$ \\
\hline NAC & 461 & 512 & 1252 & 0 & 175 & 0 \\
RAC-10 & 461 & 512 & 1127 & 125 & 175 & 5 \\
RAC-20 & 461 & 512 & 902 & 250 & 175 & 10 \\
RAC-30 & 461 & 512 & 876 & 376 & 175 & 14 \\
RAC-40 & 461 & 512 & 751 & 501 & 175 & 19 \\
RAC-50 & 461 & 512 & 626 & 626 & 175 & 24 \\
RAC-60 & 461 & 512 & 501 & 751 & 175 & 29 \\
RAC-70 & 461 & 512 & 376 & 876 & 175 & 34 \\
RAC-80 & 461 & 512 & 250 & 1002 & 175 & 38 \\
RAC-90 & 461 & 512 & 125 & 1127 & 175 & 43 \\
RAC-100 & 461 & 512 & 0 & 1252 & 175 & 48 \\
\hline
\end{tabular}

\subsection{Experimental Method}

The size of the specimen for measuring the elastic modulus was $100 \mathrm{~mm} \times 100 \mathrm{~mm} \times$ $300 \mathrm{~mm}$ and for measuring compressive strengths was $100 \mathrm{~mm} \times 100 \mathrm{~mm} \times 100 \mathrm{~mm}$ [37]. Nine specimens were made for each type of RCA replacement ratio, of which three measure compressive strength, three measure axial compressive strength, and three measure elastic modulus. After the specimens were formed, they were put in a room with a temperature of $20{ }^{\circ} \mathrm{C} \pm 5{ }^{\circ} \mathrm{C}$ and relative humidity of $50 \%$ or more for one day, and then the mold was removed. The specimens were put into a standard curing room with a temperature of $20{ }^{\circ} \mathrm{C} \pm 2{ }^{\circ} \mathrm{C}$ and relative humidity of $95 \%$ or more for 28 days after removing the mold.

The specific steps of the compressive strength test and elastic modulus test refer to China national standards GB/T 50081-2019 [37]. When measuring the elastic modulus, load to the initial load value $\mathrm{F}_{0}$ with reference stress of $0.5 \mathrm{MPa}$, the constant load for the $60 \mathrm{~s}$ was kept, and the deformation values of each measuring point in the next $30 \mathrm{~s}$ were recorded. Immediately, the load value $\mathrm{F}_{\mathrm{a}} / 3$ of the axial compressive strength was loaded continuously and uniformly, the dead load for the $60 \mathrm{~s}$ was kept, and the deformation values of each measuring point in the next $30 \mathrm{~s}$ was recorded.

\section{Results and Discussions}

\subsection{Experimental Results}

Statistical analysis was conducted by calculating the standard deviation (SD) and coefficient of variation (C.V) of the experimental results. The experimental results and statistical analysis are shown in Table 3.

Figure 3 shows the average compressive strength tested at 28 days for various replacement ratios of RCA. As seen in the figure, the strength decreases linearly with the increasing replacement ratios of RCA. This phenomenon may be attributed to the deterioration of RCA properties. Due to the large amount of original damage (internal micro-cracks) produced during the crushing and processing of RCA, its physical properties are lower than that of NCA. In addition, the adhered mortar on RCA may play a significant role in weakening the performance of RAC, particularly for strength and permeability when the water-cement ratio is the same. This may also be the reason why the strength of RAC decreased. 
Table 3. Experimental results and statistical analysis.

\begin{tabular}{cccccccc}
\hline \multirow{2}{*}{ Type } & \multirow{2}{*}{$\begin{array}{c}\text { Slump } \\
\mathbf{( m m )}\end{array}$} & $\begin{array}{c}\text { Compressive Strength } \\
\mathbf{( M P a}\end{array}$ & $\begin{array}{c}\text { SD } \\
\mathbf{( M P a})\end{array}$ & $\begin{array}{c}\text { C.V } \\
\mathbf{( \% )}\end{array}$ & $\begin{array}{c}\text { Mean } \\
\mathbf{( G P a )}\end{array}$ & $\begin{array}{c}\text { SD } \\
\mathbf{( G P a )}\end{array}$ & $\begin{array}{c}\text { C.V } \\
\mathbf{( \% )}\end{array}$ \\
\hline NAC & 49 & 33.63 & 0.74 & 2.19 & 33.96 & 0.80 & 2.35 \\
RAC-10 & 46 & 33.27 & 1.23 & 3.71 & 33.03 & 1.22 & 3.70 \\
RAC-20 & 44 & 32.87 & 1.25 & 3.80 & 32.53 & 1.32 & 4.07 \\
RAC-30 & 42 & 32.17 & 0.80 & 2.49 & 31.01 & 0.41 & 1.33 \\
RAC-40 & 47 & 31.27 & 0.85 & 2.72 & 28.91 & 0.66 & 2.27 \\
RAC-50 & 50 & 30.73 & 1.39 & 4.51 & 28.22 & 1.30 & 4.59 \\
RAC-60 & 51 & 29.83 & 0.38 & 1.27 & 29.16 & 0.77 & 2.65 \\
RAC-70 & 53 & 28.57 & 1.31 & 4.57 & 27.37 & 0.41 & 1.48 \\
RAC-80 & 53 & 28.33 & 0.42 & 1.47 & 25.70 & 0.61 & 2.37 \\
RAC-90 & 55 & 27.93 & 0.60 & 2.16 & 24.99 & 0.39 & 1.57 \\
RAC-100 & 56 & 27.60 & 0.36 & 1.31 & 24.44 & 1.02 & 4.17 \\
\hline
\end{tabular}

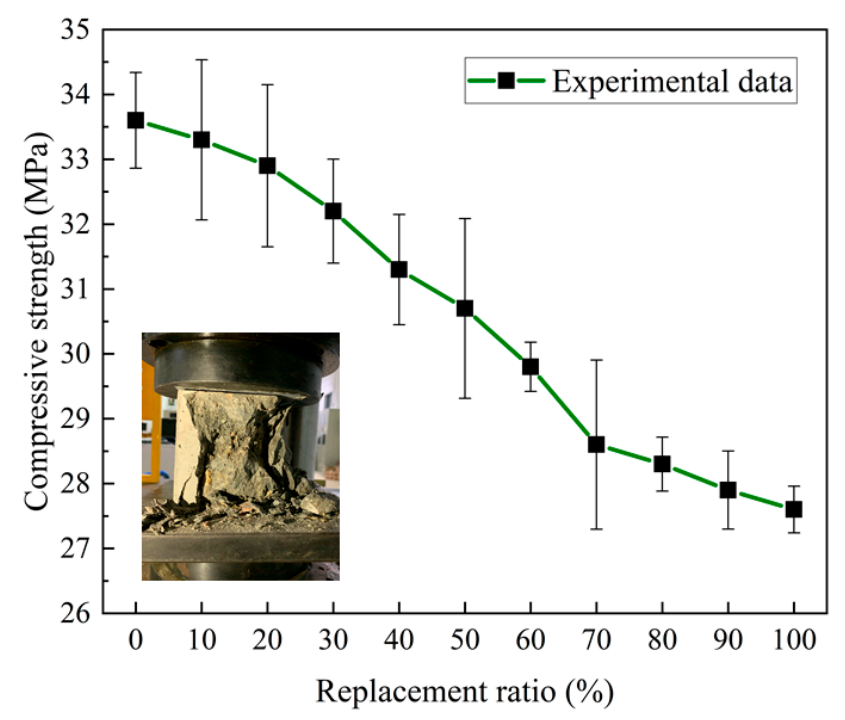

Figure 3. Experiment results of 28 day compressive strength. The error bar represents the standard deviation (SD) of the experiment data.

As shown in Figure 4, the elastic modulus of RCA is lower than that of NCA because of the porous nature of RCA. Generally speaking, the elastic modulus of RAC tends to decrease linearly with the increase in the replacement ratio of RCA. However, the elastic modulus does not fit the overall trend well due to a slight increase when the replacement ratio of RCA reaches $60 \%$. The reason for this phenomenon may be that the relationship between RCA, NCA, and mortar is not a simple inclusion under this replacement ratio of RCA but may involve more complex reasons, such as surface effects. It may also be abnormal data caused by experimental measurement errors in addition to the possible explanations mentioned above. Therefore, follow-up studies need to be conducted to explore the reasons for this phenomenon.

Based on the above work, the results of compressive strength and elastic modulus obtained from the experiment are fitted in Figure 5.

It is worth noting that there is an empirical relationship

$$
\mathrm{E}=1252.96 \sigma-123,21.17 \quad \mathrm{R}^{2}=0.9101
$$

between the compressive strength $(\sigma)$ and the elastic modulus (E).

This empirical relationship provides the theoretical basis for predicting the elastic modulus of RAC through its compressive strength. Since the mixture proportions and water-cement ratio of this experiment are constant, the influence of parameters such as the 
mixture design and water-cement ratio on this empirical relationship is currently unknown. Whether it has universal applicability requires further research and verification.

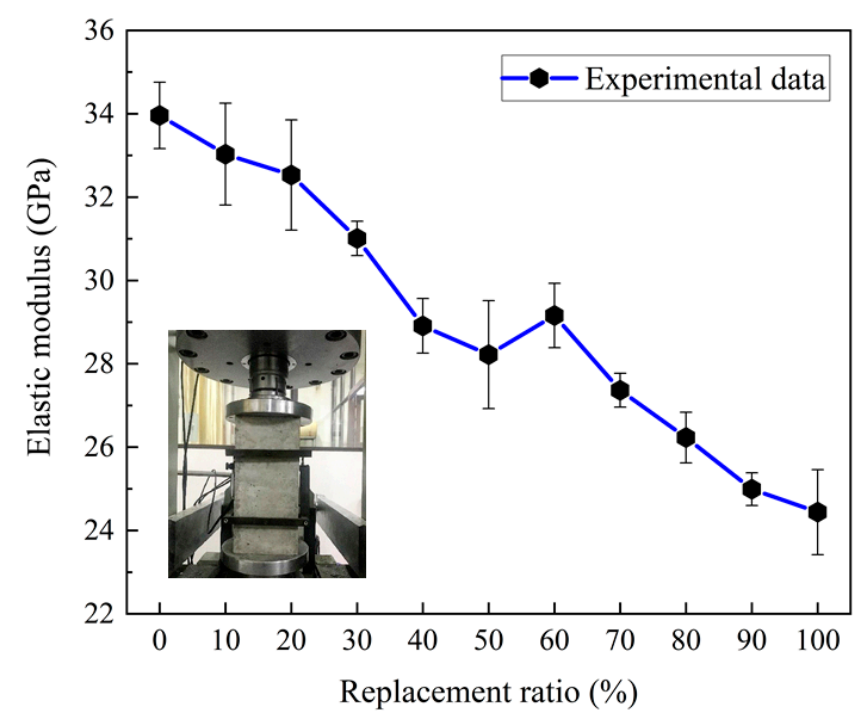

Figure 4. Experiment results of elastic modulus. The error bar represents the standard deviation (SD) of the experiment data.

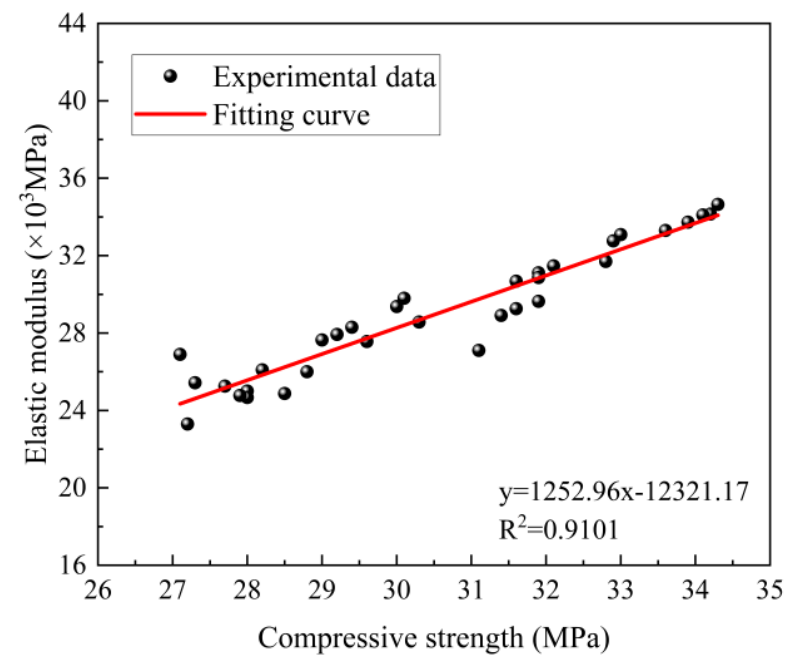

Figure 5. The relationship between compressive strength and elastic modulus.

\subsection{Comparison of Theoretical and Experimental Results}

To verify the theoretical model, the elastic modulus of RAC acquired by the four models is compared with those obtained by the experiments. In the experiment, the NCA is made of basalt after crushing and processing. Thus, the approximate values of mechanical properties of RCA, NCA, and mortar used in the calculation are listed in Table 4 according to the data from the literature [38-40]. Among them, the value of the elastic modulus of RCA is carefully selected according to the elastic modulus of NAC. Bulk modulus and shear modulus are calculated by using the elastic modulus and Poisson's ratio of NCA and RCA. 
Table 4. The mechanical properties of RCA, NCA, and mortar [38-40].

\begin{tabular}{|c|c|c|c|c|c|}
\hline Type & $\begin{array}{l}\text { Elastic Modulus } \\
\text { (GPa) }\end{array}$ & $\begin{array}{l}\text { Poisson's } \\
\text { Ratio }\end{array}$ & $\begin{array}{l}\text { Bulk Modulus } \\
\text { (GPa) }\end{array}$ & $\begin{array}{c}\text { Shear Modulus } \\
\text { (GPa) }\end{array}$ & $\begin{array}{l}\text { Density } \\
\left(\mathrm{g} / \mathrm{cm}^{3}\right)\end{array}$ \\
\hline NCA & 60.00 & 0.25 & 40.00 & 24.00 & 2.7 \\
\hline RCA & 33.96 & 0.20 & 18.87 & 14.15 & 2.6 \\
\hline Mortar & 22.00 & 0.15 & 10.48 & 9.57 & - \\
\hline $\begin{array}{l}\text { Concrete (NAC } \\
\text { and RAC) }\end{array}$ & - & - & - & - & 2.4 \\
\hline
\end{tabular}

According to the parameters provided in Table 4 and the prediction models of the elastic modulus of the RAC obtained in Section 2, the relationship between the variation curves of the different prediction models and the experimental results is shown in Figure 6.

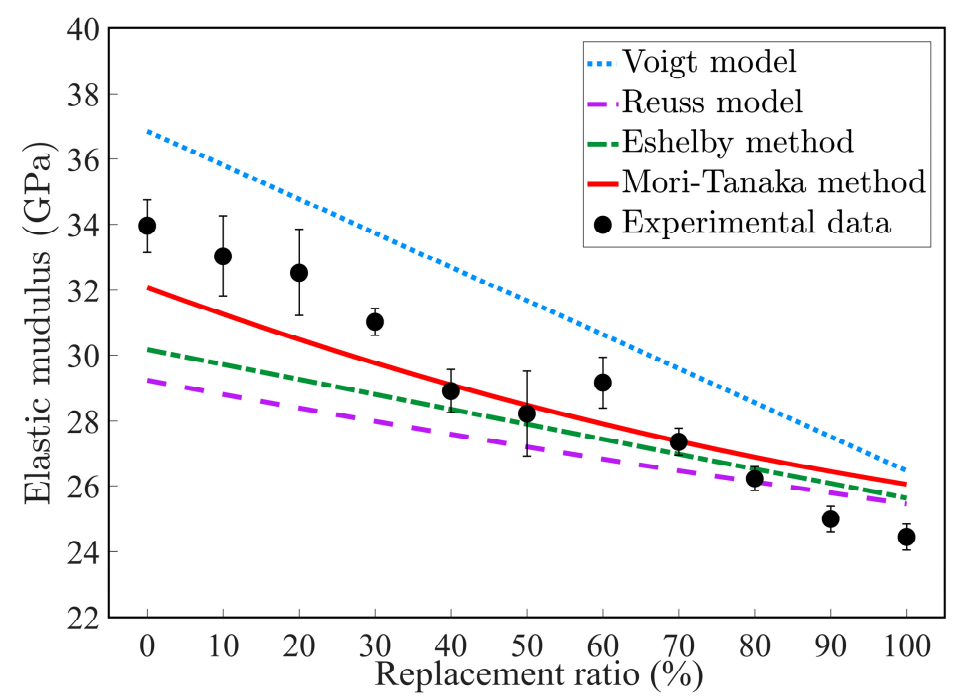

Figure 6. Comparisons of four prediction models and experimental results. The error bar in the figure represents the standard deviation of the experiment data.

It is obvious that the prediction model deduced by the Mori-Tanaka method is in good agreement with the experimental results for any replacement ratio of RCA, and the results are closer to the experimental results. What is more, it is surprising that the prediction model derived from the Voigt model is also closer to the experimental data when the replacement ratio of RCA is small (less than $30 \%$ ). When the replacement ratio of RCA is between $30 \%$ and $80 \%$, the accuracy of the prediction model derived from the Reuss model is also relatively excellent. Considering that if the elastic modulus of RAC needs predicting in engineering, the Voigt model and Reuss model can be used through simpler and faster calculations because they can produce relatively accurate results based on the appropriate replacement ratio of RCA. This advantage is not available in the Mori-Tanaka method, which is the most accurate one among the four models.

Statistical parameters associated with the prediction performances of models are enumerated in Table 5. All theoretical models produced predictions with reasonable accuracy, with the Pearson correlation coefficient $(R)$ of all models being greater than 0.95 and the root mean squared error (RMSE) ranging from 1.59 to $4.60 \mathrm{GPa}$. Based on the values of the latter, it can be said that the micromechanics-based prediction models can predict the elastic modulus of RAC made of different RCA content, within approximately \pm 5 and $\pm 2 \mathrm{GPa}$ of the actual value in the worst- and best-case scenarios, respectively. Such margins of error in predictions are reasonable considering that even in experimental measurements of the elastic modulus of RAC, the standard deviation could be as high as 1-3 GPa. On the basis of other parameters including mean absolute error (MAE) and mean absolute percentage error (MAPE), the prediction performance of the Mori-Tanaka method is more 
precise than other prediction models. Based on the statistical analysis, it was shown that micromechanics-based prediction models can accurately and reasonably predict the elastic modulus of RAC as long as they are carefully deduced and analyzed.

Table 5. Prediction performance of four models, measured on the basis of the experimental data. Five statistical parameters are shown. The best-performing model is heightened in bold.

\begin{tabular}{cccccc}
\hline Model & $\mathbf{R}$ & $\mathbf{R}^{\mathbf{2}}$ & $\begin{array}{c}\text { MAE } \\
\mathbf{( G P a )}\end{array}$ & $\begin{array}{c}\text { MAPE } \\
\mathbf{( \% )}\end{array}$ & $\begin{array}{c}\text { RMSE } \\
(\mathbf{G P a})\end{array}$ \\
\hline Voigt model & 0.9794 & 0.9593 & 2.8061 & 8.9222 & 2.8789 \\
Reuss model & 0.9766 & 0.9537 & 3.8761 & 14.3613 & 4.5913 \\
Eshelby method & 0.9759 & 0.9523 & 1.8000 & $\mathbf{6 . 3 1 8 4}$ & 2.2251 \\
Mori-Tanaka method & $\mathbf{0 . 9 8 0 4}$ & $\mathbf{0 . 9 6 1 3}$ & $\mathbf{1 . 3 5 8 1}$ & 10.8007 & $\mathbf{1 . 5 8 7 3}$ \\
\hline
\end{tabular}

In order to better illustrate the reliability and adaptability, the Mori-Tanaka method is compared with some methods for predicting the elastic modulus of concrete proposed in the previous literature $[26,41]$.

Note that the mixture designs only differ in the RCA content, and other parameters such as cement content, $\mathrm{W} / \mathrm{C}$ ratio, sand ratio, etc., were kept constant. Several experimental data from the open literature $[3,23,42]$ are employed with the data in this paper.

The comparison results of the experimental data and the predicted value of different theoretical models is shown in Figure 7. Noting the fitting curve and the coefficient of determination $\left(R^{2}\right)$, it is obvious that the predicted elastic modulus of RAC by the MoriTanaka method is closer to the experimental data, which is significantly better than the other two prediction methods.

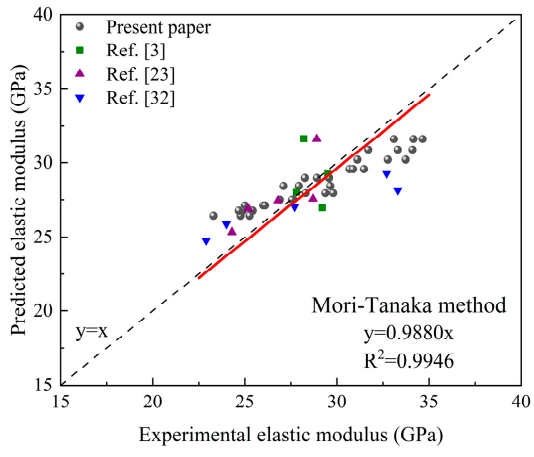

(a)

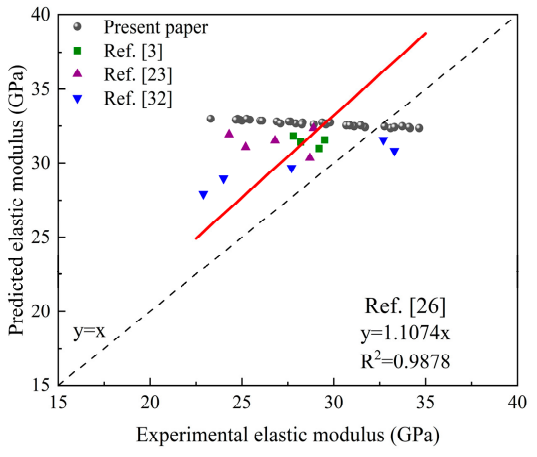

(b)

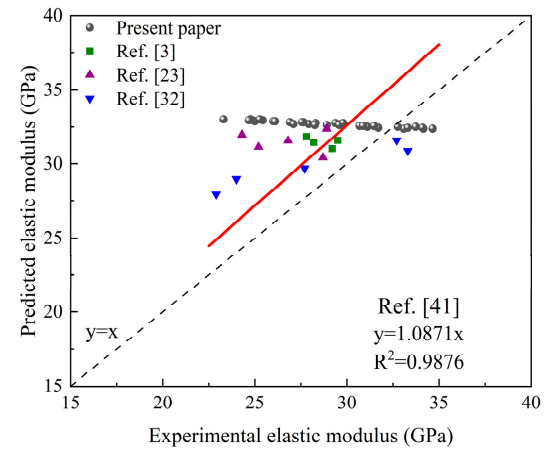

(c)

Figure 7. Predicted elastic modulus versus experimental results for different theoretical models. (a) The Mori-Tanaka method; (b) Reference [26]; and (c) Reference [41].

Statistical parameters associated with the prediction performances of three models are enumerated in Table 6. It is found that the Mori-Tanaka method gives the best overall approximation for various data. The properties of experimental data from the available literature such as the type of NCA raw stone, the strength of RCA, etc., are not known as well as the experiment in this paper. Hence, its accuracy would be improved further after adjusting based on the situation of the specific experiment. As for the other two theoretical prediction models obtained from the previous literature, their accuracy and applicability are significantly reduced when they are employed to predict the elastic modulus of RAC. Therefore, they need to make appropriate corrections to improve its reliability when they are applied in the case of RAC. 
Table 6. Prediction performance of three models, measured on the basis of the different experimental data. Five statistical parameters are shown. The best-performing model is highlighted in bold.

\begin{tabular}{cccccc}
\hline Model & $\mathbf{R}$ & $\mathbf{R}^{\mathbf{2}}$ & $\begin{array}{c}\text { MAE } \\
\mathbf{( G P a )}\end{array}$ & $\begin{array}{c}\text { MAPE } \\
\mathbf{( \% )}\end{array}$ & $\begin{array}{c}\text { RMSE } \\
(\mathrm{GPa})\end{array}$ \\
\hline $\begin{array}{c}\text { Mori-Tanaka method } \\
\text { Reference [26] }\end{array}$ & $\mathbf{0 . 7 6 7 8}$ & $\mathbf{0 . 5 8 9 5}$ & $\mathbf{1 . 6 5 3 8}$ & $\mathbf{5 . 8 1 3 7}$ & $\mathbf{2 . 0 3 5 4}$ \\
Reference [41] & 0.3037 & 0.0922 & 3.7848 & 11.9413 & 4.4411 \\
\hline
\end{tabular}

\section{Conclusions}

This paper adopts four models to predict the elastic modulus of RAC based on micromechanics. The compressive strength and elastic modulus experiments of RAC are conducted to verify the accuracy and robustness of the prediction models. Some methods for predicting the elastic modulus of concrete proposed in the previous literature are employed to be compared with the most satisfactory one in this paper. Several experimental data from the open literature are also utilized with the experiment of this paper to better illustrate the reliability of the prediction models. Based on the above research, it can be concluded that:

1. Both compressive strength and the elastic modulus of RAC tend to decrease with the increase in the replacement ratio of RCA. However, the elastic modulus does not fit the overall trend well when the replacement ratio of RCA reaches $60 \%$. In addition, there is an empirical relationship between the compressive strength and the elastic modulus. Further research needs to be conducted to verify the correctness and applicability of this linear relationship.

2. Of the four prediction models, the Mori-Tanaka method is the most accurate and reasonable. The accuracy of the Voigt model or the Reuss model fits relatively well respectively when the replacement ratio is within a certain range. As far as engineering is concerned, the Voigt model or the Reuss model can also be employed because of their simple calculation to obtain a relatively accurate elastic modulus of RAC conveniently.

3. The Mori-Tanaka method gives the best overall approximation for various data compared to the prediction models obtained from the previous literature. Moreover, it illustrates the extensive effects of the Mori-Tanaka method in predicting the elastic modulus of RAC.

Author Contributions: Conceptualization, S.Y. and B.W.; methodology, S.Y.; validation, S.Y. and B.W.; formal analysis, S.Y.; investigation, S.Y. and B.L.; resources, B.W.; data curation, S.Y. and Y.S.; writing - original draft preparation, S.Y.; writing—review and editing, S.Y. and B.W.; supervision, B.W.; project administration, B.W.; funding acquisition, B.W. All authors have read and agreed to the published version of the manuscript.

Funding: This research was funded by Key Technology Research and Development Program of Shandong, grant number 2019GSF109022.

Acknowledgments: Experimental and computational tasks, described in this study, were conducted in Taian (Shandong University) Urban and Rural Solid Waste Comprehensive Utilization Research Institute.

Conflicts of Interest: The authors declare no conflict of interest.

\section{References}

1. Liu, T.; Teng, Y.; Wang, D.; Gong, E. System dynamic analysis of construction waste recycling industry chain in China. Environ. Sci. Pollut. Res. Int. 2020, 27, 37260-37277. [CrossRef]

2. GB/T 25177-2010. Recycled Coarse Aggregate for Concrete; Ministry of Housing and Urban-Rural Development of the People's Republic of China: Beijing, China, 2010.

3. Ho, N.Y.; Lee, Y.P.K.; Lim, W.F.; Zayed, T.; Chew, K.C.; Low, G.L.; Ting, S.K. Efficient Utilization of Recycled Concrete Aggregate in Structural Concrete. J. Mater. Civ. Eng. 2013, 25, 318-327. [CrossRef] 
4. Karimipour, A.; Edalati, M. Influence of untreated coal and recycled aggregates on the mechanical properties of green concrete. J. Clean Prod. 2020, 276, 124291. [CrossRef]

5. Xiao, J.Z.; Lu, D.; Ying, J.W. Durability of recycled aggregate concrete: An overview. J. Adv. Concr. Technol. 2013, 11, 347-359. [CrossRef]

6. Chinzorigt, G.; Lim, M.K.; Yu, M.; Lee, H.; Enkbold, O.; Choi, D. Strength, shrinkage and creep and durability aspects of concrete including $\mathrm{CO}_{2}$ treated recycled fine aggregate. Cem. Concr. Res. 2020, 136, 106062. [CrossRef]

7. Rais, M.S.; Khan, R.A. Effect of biomineralization technique on the strength and durability characteristics of recycled aggregate concrete. Constr. Build. Mater. 2021, 290, 123280. [CrossRef]

8. Gupta, P.K.; Rajhans, P.; Panda, S.K.; Nayak, S.; Das, S.K. Mix design method for self-compacting recycled aggregate concrete and its microstructural investigation by considering adhered mortar in aggregate. J. Mater. Civ. Eng. 2020, 32, 04019371. [CrossRef]

9. Kazmi, S.M.S.; Munir, M.J.; Wu, Y.F.; Patnaikuni, I.; Zhou, Y.W.; Feng, X. Effect of different aggregate treatment techniques on the freeze-thaw and sulfate resistance of recycled aggregate concrete. Cold Reg. Sci. Tech. 2020, 178, 103126. [CrossRef]

10. Ahmed, T.W.; Ali, A.M.; Zidan, R.S. Properties of high strength polypropylene fiber concrete containing recycled aggregate. Constr. Build. Mater. 2020, 241, 118010. [CrossRef]

11. Bidabadi, M.S.; Akbari, M.; Panahi, O. Optimum mix design of recycled concrete based on the fresh and hardened properties of concrete. J. Build. Eng. 2020, 32, 101483. [CrossRef]

12. Zhang, H.; Wang, Y.Y.; Lehman, D.E.; Kuder, K. Time-dependent drying shrinkage model for concrete with coarse and fine recycled aggregate. Cem. Concr. Compos. 2019, 105, 103426. [CrossRef]

13. Gholampour, A.; Ozbakkaloglu, T. Time-dependent and long-term mechanical properties of concretes incorporating different grades of coarse recycled concrete aggregates. Eng. Struct. 2018, 157, 224-234. [CrossRef]

14. Ayub, T.; Mahmood, W.; Khan, A. Durability performance of SCC and SCGC containing recycled concrete aggregates: A comparative study. Sustainability 2021, 13, 8621. [CrossRef]

15. Ying, J.W.; Zhou, B.; Xiao, J.Z. Pore structure and chloride diffusivity of recycled aggregate concrete with nano-SiO ${ }_{2}$ and nano-TiO 2 . Constr. Build. Mater. 2017, 150, 49-55. [CrossRef]

16. Kazmi, S.M.S.; Munir, M.J.; Wu, Y.F. Application of waste tire rubber and recycled aggregates in concrete products: A new compression casting approach. Resour. Conserv. Recycl. 2021, 167, 105353. [CrossRef]

17. Sadowska-Buraczewska, B.; Barnat-Hunek, D. Szafraniec, M. Influence of recycled high-performance aggregate on deformation and load-carrying capacity of reinforced concrete beams. Materials 2020, 13, 186. [CrossRef] [PubMed]

18. Deresa, S.T.; Xu, J.J.; Demartino, C.; Heo, Y.; Li, Z.; Xiao, Y. A review of experimental results on structural performance of reinforced recycled aggregate concrete beams and columns. Adv. Struct. Eng. 2020, 23, 3351-3369. [CrossRef]

19. Khelil, A.; Boissiere, R.; Al Mahmoud, F.; Wurtzer, F.; Blin-Lacroix, J.L. Experimental and numerical investigation on axial compression of reinforced concrete columns made from recycled coarse and fine aggregates. Struct. Concr. 2020, 22, 193-206. [CrossRef]

20. Xiao, J.Z. Recycled Aggregate Concrete Structures; Springer: Berlin/Heidelberg, Germany, 2018. [CrossRef]

21. Bendimerad, A.Z.; Delsaute, B.; Roziere, E.; Staquet, S.; Loukili, A. Advanced techniques for the study of shrinkage-induced cracking of concrete with recycled aggregates at early age. Constr. Build. Mater. 2020, 233, 17340. [CrossRef]

22. Barbudo, A.; de Brito, J.; Evangelista, L.; Bravo, M. Influence of water-reducing admixtures on the mechanical performance of recycled concrete. J. Clean. Prod. 2013, 59, 93-98. [CrossRef]

23. Corinaldesi, V. Mechanical and elastic behaviour of concretes made of recycled-concrete coarse aggregates. Constr. Build. Mater. 2010, 24, 1616-1620. [CrossRef]

24. Golafshani, E.M.; Behnood, A. Application of soft computing methods for predicting the elastic modulus of recycled aggregate concrete. J. Clean. Prod. 2018, 176, 1163-1176. [CrossRef]

25. Han, T.H.; Siddique, A.; Khayat, K.; Huang, J.; Kumar, A. An ensemble machine learning approach for prediction and optimization of modulus of elasticity of recycled aggregate concrete. Constr. Build. Mater. 2020, 244, 118271. [CrossRef]

26. Counto, U.J.; Mears, A.R.; Ishai, O.; Chiorino, M.A. Discussion: The effect of the elastic modulus of the aggregate on the elastic modulus, creep and creep recovery of concrete. Mag. Concr. Res. 1965, 17, 142-151. [CrossRef]

27. Chang, C.F.; Chen, J.W. Strength and Elastic Modulus of Carbonated Concrete. ACI Mater. J. 2005, 102, 315-321.

28. Voigt, W. Uber die Beziehung Zwischen Den Beiden Elastiziatskonstanten Isotroper Korper. Wied. Ann. 1889, 38, 573-578. [CrossRef]

29. Reuss, A.Z. Berchung der Fiessgrenze von Mischkristallen auf Grund der Plastiziatsbedingung fur Einkristalle. Angew. Math. Mach. 1929, 9, 49-58. [CrossRef]

30. Eshelby, J.D. The Determination of the Elastic Field of an Ellipsoidal Inclusion, and Related Problems. Proc. R. Soc. A 1957, 241, 376-396. [CrossRef]

31. Eshelby, J.D. The Elastic Field outside an Ellipsoidal Inclusion. Proc. R. Soc. A 1959, 252, 561-569. [CrossRef]

32. Qu, J.M.; Cherkaoui, M. Fundamentals of Micromechanics of Solids; John Wiley \& Sons, Inc.: Hoboken, NJ, USA, 2006.

33. Mori, T.; Tanaka, K. Average stress in matrix and average elastic energy of materials with misfitting inclusions. Acta Metall. 1973, 21, 571-574. [CrossRef]

34. GB/T 14684-2011. Sand for Construction; China Building Materials Federation: Beijing, China, 2011.

35. GB/T 14685-2011. Pebble and Crushed Stone for Construction; China Building Materials Federation: Beijing, China, 2011. 
36. Zhang, Y.M.; Qin, H.G.; Sun, W.; Hao, D.M.; Ning, Z. The mix proportion design of recycled concrete. Concr. Cem. Prod. 2002, 1, 7-9. [CrossRef]

37. GB/T 50081-2019. Standard for Test Methods of Concrete Physical and Mechanical Properties; Ministry of Housing and Urban-Rural Development of the People's Republic of China: Beijing, China, 2019.

38. Zheng, J.J.; Chen, T.; Zhou, X.Z.; Zhou, H. Analytical solution for the elastic modulus of recycled concrete. Concrete 2019, 3, 40-43. [CrossRef]

39. Zhou, H.Y.; Li, S.C.; Duan, Z.; Wang, M.L.; Zhi, B. Study on the preparation of similar basalt materials and their physical and mechanical parameters. Yangtze River 2021, 52. [CrossRef]

40. Gil, H.; Ortega, A.; Pérez, J. Mechanical behavior of mortar reinforced with sawdust waste. Procedia Eng. 2017, 200, 325-332. [CrossRef]

41. Hirsch, T.J. Modulus of elasticity of concrete affected by elastic moduli of cement paste matrix and aggregate. Proc. Am. Concr. Inst. 1962, 59, 427-451.

42. Luo, S.R.; Ye, S.C.; Xiao, J.Z.; Zhu, Y.T. Carbonated recycled coarse aggregate and uniaxial compressive stress-strain relation of recycled aggregate concrete. Constr. Build. Mater. 2018, 188, 956-965. [CrossRef] 